\title{
BREAST CANCER AWARENESS AND ATTITUDE AMONG NURSES OF A TERTIARY CARE CENTRE OF SUB-HIMALAYAN REGION
}

\author{
Ratti Ram Negi', Mitasha Singh², Ankush Kaushal33, Sunil Kumar Raina ${ }^{4}$ \\ ${ }^{1}$ Assistant Professor, Department of Radiotherapy, Dr. Rajendra Prasad Government Medical College, Kangra, Tanda, Himachal \\ Pradesh. \\ ${ }^{2}$ Assistant Professor, Department of Community Medicine, ESIC Medical College, Faridabad, Haryana. \\ ${ }^{3}$ Medical Social Worker, Department of Community Medicine, Dr. Rajendra Prasad Government Medical College, Kangra, Tanda, \\ Himachal Pradesh. \\ ${ }^{4}$ Associate Professor, Department of Community Medicine, Dr. Rajendra Prasad Government Medical College, Kangra, Tanda.
}

ABSTRACT
BACKGROUND
The frontline workers including nurses need to be focused in creating awareness and reducing the cultural and emotional barrier
about breast screening among the female patients and community they come across. The objective of the study is to determine the
knowledge and attitude regarding risk factors, symptoms and screening of breast cancer among nursing students and staff of a
tertiary care centre.

\section{MATERIALS AND METHODS}

A cross sectional survey was conducted among 300 nursing students and staff of Dr. Rajendra Prasad Government Medical College, Kangra at Tanda, Himachal Pradesh in 2016. A semi-structured predesigned study tool was introduced to assess the demographic profile and knowledge and attitude regarding risk factor and symptoms pertaining to breast cancer.

\section{RESULTS}

The adequate knowledge about all risk factors was observed among 15.3\% nurses. Around 40\% of nurses had correct knowledge about ways of preventing BC and even higher proportion about techniques of early BC detection (63.3\%). The age and year of practice duration did show a difference; with younger age and students being more knowledgeable but this distribution was not significant. The serious and positive attitude towards seeking medical help of BC was higher among married and higher age group nurses.

\section{CONCLUSION}

Along with increasing knowledge we have to strengthen emotional status of women in our country. The frontline workers can prove to be a great asset in creating community awareness.

\section{KEYWORDS}

Awareness, Breast Cancer, Frontline Workers, Risk, Prevention.

HOW TO CITE THIS ARTICLE: Negi RR, Singh M, Kaushal A, et al. Breast cancer awareness and attitude among nurses of a tertiary care centre of Sub-Himalayan region. J. Evolution Med. Dent. Sci. 2017;6(33):2710-2713, DOI: 10.14260/Jemds/2017/585

\section{BACKGROUND \\ Breast cancer (BC) is a major public health problem in developed nations and is becoming an increasingly predominant problem in low and middle income countries, where incidence rates have increased by up to $5 \%$ per year. ${ }^{1,2}$ The incidence of breast cancer is increasing in the developing world due to increased life expectancy, increased urbanisation and adoption of western lifestyles. \\ The common risk factors include female gender, increasing age, family history of $\mathrm{BC}$, early menarche, late menopause, older age at first live childbirth, genetic mutation, diet, obesity, smoking, and alcohol consumption.2, 3 Many of the breast cancer cases in developing countries including India are diagnosed in advanced stages,}

Financial or Other, Competing Interest: None.

Submission 19-03-2017, Peer Review 13-04-2017

Acceptance 18-04-2017, Published 24-04-2017.

Corresponding Author:

Dr. Mitasha Singh,

Department of Community Medicine,

ESIC Medical College, Faridabad,

Haryana.

E-mail: mitasha.17@gmail.com

DOI: $10.14260 /$ jemds $/ 2017 / 585$

\section{(c) $(1) \ominus$}

attributable to low level of awareness about early warning signs and screening methods among general women population and poor prognosis of the patients. Correct knowledge about early warning signs and screening methods of disease plays an effective role towards developing and employing early detection programs in a community. ${ }^{4}$

There is a dearth of large scale breast screening programs in India. Breast Self-Examination (BSE) is advocated, but data on what proportion it is exercised is not available. ${ }^{5}$ BSE is an appropriate, convenient and cost effective method that can be done by every woman with little training. Nearly all Indian breast cancers are clinically detected; almost none are detected by screening. ${ }^{6}$ Nurses constitute one group of health workers who are more frequently in contact with patients and their relations than other healthcare professionals. In view of the roles nurses are expected to play in breast care, this study was conducted among nurses working in a tertiary centre of North India to determine their knowledge and attitude towards breast cancer risk factors and prevention.

\section{MATERIALS AND METHODS}

The cross-sectional study was conducted in a nursing school at Dr. Rajendra Prasad Government Medical College, Kangra at Tanda, HP from September to December of 2016. 
The survey was designed to investigate the sociodemographic background of the respondents and their level of knowledge and attitudes on breast cancer, its risk factor, prevention and early detection. Taking prevalence of good knowledge among similar group of participants from literature as $25.2 \%$, absolute error as $5 \%$ and at $95 \%$ confidence interval, the minimum sample size was calculated to be 290 using Epi info v7.6 We approached 310 nurses to account for attrition.

The study was conducted in a case study mode using convenience sampling among nursing students and staff at the college and hospital. The study was initiated after approval from institute's ethical committee.

There were three batches of nursing students (General nursing diploma; GNM) with 40 students in each. The respective batches of nursing students with internship batch were approached in their classes after prior permission from their principal and the participants were explained the procedure and purpose of data collection. The seating arrangement was such that one participant was seated at such a distance from the next participant that they could not talk to each other. This was done by keeping a gap of two benches between the participants. Hence a total of 120 students were approached of which 119 participated in the survey; one refused to participate. The staff posted in general and private wards of the hospital (around 20 wards) were approached. The nurses worked in three shifts in a day with minimum two and maximum four nurses on duty at one point of time. Before proceeding to their duties or at the end of the duty hours they were invited in lecture theatres and the same procedure as above were performed for data collection. A total of 190 nurses were approached and 181 consented to participate. Hence, 300 nurses consented and handed over the complete proforma.

A self-administered semi-structured questionnaire to obtain information regarding sociodemographic characteristics, knowledge, and attitude towards breast cancer was developed by an expert group comprising of one oncologist, two public health specialists, a medical social worker and a nursing superintendent from the tertiary care centre. After arriving at consensus on all the questions of the questionnaire developed, the piloting was performed. A random sample of 25 staff nurses and students (from other nursing college attending the study area for their practical classes) were approached starting from the first ward on entrance of the hospital premises. Two nurses (one staff nurse on duty and other student) from each ward were approached and the process was repeated in similar manner till sample of 25 was achieved. The potential problems in the applicability of the tool were addressed and amended.

Before commencement of data collection respondents consent to participate was obtained. The questionnaire included questions on sociodemographic profile, relating to age, educational status, place of residence and marital status, and specific questions about knowledge of the risk factors, prevention and common symptoms and signs of breast cancer and diagnostic procedures available for the disease, as well as attitude towards breast cancer and skills of breast self-examination (BSE).

Knowledge regarding risk factors, symptoms, prevention and screening noted as correct or incorrect. All the correct responses to each of the subsections of knowledge related questions were given a score of one and the wrong answer or 'don't know' response were scored zero respectively. After adding up the scores of each question, the maximum score with correct answer was coded as correct. Attitude was measured by a set of five positive attitude questions using an abridged Likert's scale with responses including 'agree', 'disagree' and 'uncertain'. A score of 1 was given to a response of 'Agree' and zero score was given for two types of responses; (1) 'Uncertain', (2) 'Disagree'. Practice was assessed on possessing skills of BSE, teaching and taking about BC as a binary response. All data were analysed using Epi info version. ${ }^{7}$

\section{RESULTS}

Correct knowledge regarding risk factors, symptoms and methods of early detection of breast cancer among nursing staff and students of tertiary care centre ranged from $15 \%$ to $63 \%$. Correct knowledge regarding risk factors was observed among $15.3 \%$ of the study population; which was maximum among older age group nurses (33.3\%). There was no significant difference between married and single women with respect to knowledge about risk factors. The proportion of nurses with correct knowledge about ways of preventing BC was $(40.3 \%)$ higher than that of about risk factors. This was observed in majority among $>50$ and 21-30 years age group and students, however, the age and experience wise distribution was statistically not significant. Less than half (46.3\%) of the population was aware of symptoms of BC and this was higher among middle age (31-40 years; $49.4 \%)$ and single nurses (49.2\%) as compared to other age groups and married nurses. Majority of nurses had correct knowledge about techniques of early detection of BC (63.3\%). This was observed more among students and younger age group nurses. (Table 1)

Around $88 \%$ thought BC as serious and curable. Seeking medical consultancy in case of lump in breast was reported by $59.7 \%$; while $87 \%$ said that they will seek help immediately. Only $32.7 \%$ of the study population after sensitising them about the risk factors of BC felt that they have the risk of developing it. The serious and positive attitude towards seeking medical help of BC was higher among married and higher age group nurses. (Table 2).

Majority of nurses $(90.0 \%)$ talked about BC prevention with patients, friends and family and also felt (90.3\%) that their occupation is important for BC screening and prevention. Around two third of the nurses (67.0\%) reported that they possess the skills of breast self-examination. (Figure 1). 


\begin{tabular}{|c|c|c|c|c|c|c|c|c|}
\hline & $\begin{array}{c}\text { Knowledge } \\
\text { about ways of } \\
\text { Preventing BC }\end{array}$ & $P$ value & $\begin{array}{c}\text { Knowledge } \\
\text { about risk } \\
\text { Factors of BC }\end{array}$ & $P$ value & $\begin{array}{c}\text { Knowledge } \\
\text { about } \\
\text { Symptoms } \\
\text { of BC }\end{array}$ & $P$ value & $\begin{array}{c}\text { Knowledge about } \\
\text { Techniques of early } \\
\text { Detection of BC }\end{array}$ & $\begin{array}{c}P \\
\text { value }\end{array}$ \\
\hline Total & $121(40.3)$ & & $46(15.3)$ & & $139(46.3)$ & & $190(63.3)$ & \\
\hline \multicolumn{9}{|l|}{ Age groups } \\
\hline$\leq 20$ & $26(36.1)$ & 0.52 & $15(20.8)$ & 0.31 & $33(45.8)$ & 0.55 & $50(69.4)$ & 0.19 \\
\hline $21-30$ & $56(45.2)$ & & $14(11.3)$ & & $59(47.6)$ & & $73(58.9)$ & \\
\hline $31-40$ & $30(39.0)$ & & $12(15.6)$ & & $38(49.4)$ & & $52(67.5)$ & \\
\hline $41-50$ & $6(28.6)$ & & $3(14.3)$ & & $8(38.1)$ & & $10(47.6)$ & \\
\hline$>50$ & $3(50.0)$ & & $2(33.3)$ & & 1 (16.7) & & $5(83.3)$ & \\
\hline \multicolumn{9}{|l|}{ Marital status } \\
\hline Single & $56(45.9)$ & 0.12 & $20(16.4)$ & 0.74 & $60(49.2)$ & 0.48 & $82(67.2)$ & 0.27 \\
\hline Married & $65(36.5)$ & & $26(14.6)$ & & $79(44.4)$ & & $108(60.7)$ & \\
\hline \multicolumn{9}{|l|}{$\begin{array}{c}\text { Years of } \\
\text { experience }\end{array}$} \\
\hline Nil (student) & $44(44.0)$ & 0.86 & $19(19.0)$ & 0.53 & $54(54.0)$ & 0.23 & $66(66.0)$ & 0.52 \\
\hline$\leq 5$ & $22(44.0)$ & & $9(18.0)$ & & $18(36.0)$ & & $36(72.0)$ & \\
\hline $6-10$ & $45(37.5)$ & & $16(13.3)$ & & $52(43.3)$ & & $70(58.3)$ & \\
\hline $11-15$ & $6(35.3)$ & & $1(5.9)$ & & $7(41.2)$ & & $9(52.9)$ & \\
\hline $16-20$ & $2(33.3)$ & & 1 (16.7) & & $3(50.0)$ & & $4(66.7)$ & \\
\hline$>20$ & $2(28.6)$ & & 0 & & $5(71.4)$ & & $5(71.4)$ & \\
\hline
\end{tabular}

\begin{tabular}{|c|c|c|c|c|c|}
\hline & $\mathrm{BC}$ is Serious & $\mathrm{BC}$ is Curable & $\begin{array}{l}\text { Consult a Medical } \\
\text { Personnel on } \\
\text { Developing a Lump }\end{array}$ & $\begin{array}{l}\text { Time in which } \\
\text { doctor will be } \\
\text { Consulted } \\
\text { (Immediately) }\end{array}$ & $\begin{array}{c}\text { Think that you } \\
\text { have risk of } \\
\text { Developing BC } \\
\text { (Yes) }\end{array}$ \\
\hline Total & $264(88.0)$ & 265 (88.3) & $179(59.7)$ & $261(87.0)$ & $98(32.7)$ \\
\hline \multicolumn{6}{|l|}{ Age groups } \\
\hline$\leq 20$ & $64(88.9)$ & $52(72.2)$ & $41(56.9)$ & $54(75.0)$ & $21(29.2)$ \\
\hline $21-30$ & $106(85.5)$ & $115(92.7)$ & $75(60.5)$ & $106(85.5)$ & $44(35.5)$ \\
\hline $31-40$ & $69(89.6)$ & $74(96.1)$ & $47(61.0)$ & $74(96.1)$ & $27(35.1)$ \\
\hline $41-50$ & $21(100.0)$ & $20(95.2)$ & $11(52.4)$ & $21(100.0)$ & $6(28.6)$ \\
\hline$>50$ & $4(66.7)$ & $4(66.7)$ & $5(83.3)$ & $6(100.0)$ & 0 \\
\hline \multicolumn{6}{|l|}{ Marital status } \\
\hline Single & $110(90.2)$ & $98(80.3)$ & $70(57.4)$ & $93(76.2)$ & $44(36.1)$ \\
\hline Married & $154(86.5)$ & $167(93.8)$ & $109(61.2)$ & $168(94.4)$ & $54(30.3)$ \\
\hline \multicolumn{6}{|l|}{$\begin{array}{c}\text { Years of } \\
\text { experience }\end{array}$} \\
\hline Nil (student) & $90(90.0)$ & $78(78.0)$ & $57(57.0)$ & $76(76.0)$ & $37(37.0)$ \\
\hline$\leq 5$ & $44(88.0)$ & $40(80.0)$ & $37(74.0)$ & $45(90.0)$ & $11(22.0)$ \\
\hline $6-10$ & $100(83.3)$ & $118(98.3)$ & $68(56.7)$ & $110(91.7)$ & $41(34.2)$ \\
\hline $11-15$ & $17(100.0)$ & $17(100.0)$ & $9(52.9)$ & $17(100.0)$ & $7(41.2)$ \\
\hline $16-20$ & $6(100.0)$ & $5(83.3)$ & $5(83.3)$ & $6(100.0)$ & $1(16.7)$ \\
\hline$>20$ & $7(100.0)$ & $7(100.0)$ & $3(42.9)$ & $7(100.0)$ & $1(14.3)$ \\
\hline
\end{tabular}

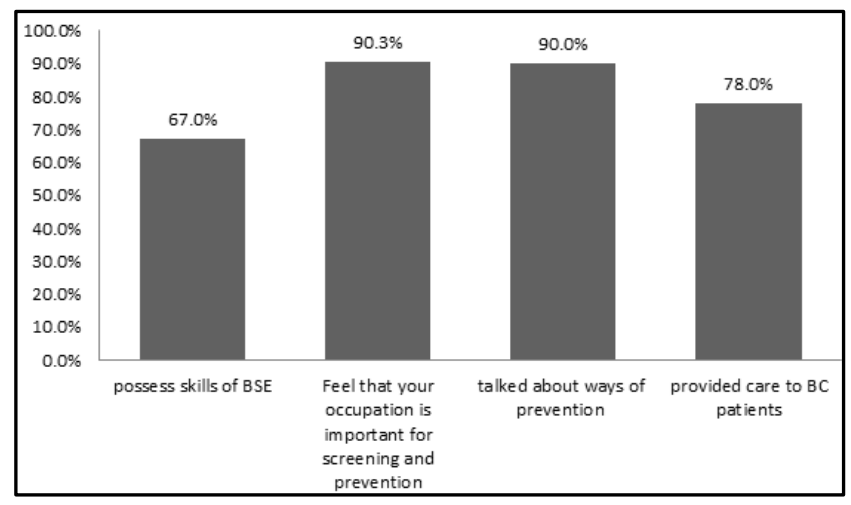

Figure 1. Practice of Nursing Staff and Students of Tertiary Care Centre, Himachal Pradesh Regarding BC

\section{DISCUSSION}

Westernisation of lifestyles will continue to increase leading to increase in incidence of breast cancer in developing countries. Low and middle income countries like India with double burden of breast and cervical cancers need cost effective interventions. ${ }^{7}$ Public education, an important component of early detection, must be sensitive to the culture and in the language of the region. All health staff and especially female staff whom women may approach first, must be able to recognise the risk factors, signs and symptoms of early as well as advanced breast cancer and must be able to refer patients for further diagnosis and treatment. Nurses are the frontline health staff and their knowledge, attitude and practices can predict the early diagnosis in the region. ${ }^{8}$

The current study area caters the majority of tribal and rural patients and population of Himachal Pradesh. It was observed that correct knowledge about all the risk factors of breast cancer among the nurses was very low. This was better than the study on nurses of Nigeria where only $27 \%$ 
understood three of the risk factors and none knew all five. ${ }^{9}$ Fotedar et al reported a higher proportion of knowledge about risk factors among nurses of Shimla district.10 However, the knowledge about preventive measures among the study population was higher. Overall knowledge about symptoms was adequate (all symptoms knowledge) among $46.3 \%$ of nurses. This was lower as compared to Nigerian nurses but comparable to the knowledge of nurses from a different district of same state.9,10 The knowledge about techniques of early detection that is BSE, clinical examination and mammography was observed to be adequate among majority of the nurses. This was higher as reported by Nigerian health workers, but lower as compared to nurses from other districts of the state.10,11 Although the knowledge about risk factors and symptoms of BC was low, techniques of early detection were known among majority.

Attitude towards BC symptoms, screening and early detection in terms of seriousness and seeking care was reported by majority of the nurses. This finding is comparable to the attitude of Nigerian nurses. ${ }^{9}$ A positive attitude is needed to bring about the knowledge into practice. So the frontline workers can prove as good role models for creating awareness among general population about breast cancer screening programmes. ${ }^{11}$ However, in the current analysis, the attitude was strong among married and old age nurses. This is in contrast to the notion that in the cultural setting of our country that the older and married women have a nonchalant attitude and are of the opinion that they have led a relatively disease free life so far and being married would prevent the disease now. ${ }^{12}$ Hence a positive attitude among this group of health care providers would benefit the women of community.

Around two third of the nurses reported of having BSE skills. It was lower among Nigerian urban female health workers but higher among community-dwelling women of Nigeria with $87.2 \%$ score. ${ }^{10,13}$ Evidence suggests that the stigma of being rejected by the community and partner, potential fear of loss of breast and an obstacle of being the prevailing taboo of not discussing breast cancer topic openly are the barriers of health care seeking behaviour in our country. However, majority of nurses in this study talk about $\mathrm{BC}$ among patients, family and friends. Hence, these frontline female staff of our country is the key towards creating awareness and changing the attitude of the general population towards breast cancer screening procedures.

In a country where resources are constrained and if the majority of breast cancer patients are presenting in advanced stages, the introduction of a well-organised early diagnosis programme including BSE and clinical breast examination could, in the long-term, significantly improve survival and reduce mortality from breast cancer. 14

The convenient sampling used and single centre being involved limits us to generalise the findings to all the health care providers of the country. The data collected from interview of respondents may be subjected to response bias. People tend to provide socially desirable responses and moreover there are differences in levels of perception of the questions asked.

\section{CONCLUSION}

Our study participants did not have adequate knowledge on risk factors and symptoms of BC. However, the knowledge about prevention and early detection was observed among majority with a healthy attitude among nurses towards BC. At present, the only cancer for which there is good evidence that screening can reduce mortality are breast, cervix, colorectum and possibly oral cancer. ${ }^{14}$ Along with increasing knowledge we have to strengthen emotional status of women be it health care workers or general population. Hence, a policy to empower nursing staff, female health workers and accredited social health activists in BC screening programme could overcome a number of obstacles majorly faced by females from remote areas of country. 15

\section{REFERENCES}

[1] Stewart BW, Kleihues P. World cancer report. Tech. Rep. International Agency for Research on Cancer, Lyon, France, 2003.

[2] Khatib OM, Modjtabai A. Guidelines for the early detection and screening of breast cancer. World Health Organization, Regional Office for the Eastern Mediterranean, 2006.

[3] National Comprehensive Cancer Network, "NCCN clinical practice guidelines in oncology: breast cancer. Version 2." http:// www.nccn.org/ professionals/ physician gls/f guidelines.asp.

[4] Elmore JG, Armstrong K, Lehman CD, et al. Screening for breast cancer. JAMA 2005;293(10):1245-56.

[5] Singh S, Shrivastava JP, Dwivedi A. Breast cancer screening existence in India: a non-existing reality. Indian J Med Pediatr Oncol 2015;36(4):207-9.

[6] Agarwal G, Ramakant P. Breast cancer care in India: the current scenario and the challenges for the future. Breast Care 2008;3(1):21-7.

[7] World Health Organization. Cancer. http://www.who.int/topics/cancer/en/ Accessed on March 19, 2017.

[8] Yip CH, Smith RA, Anderson BO, et al. Guideline implementation for breast healthcare in low-and middle-income countries: early detection resource allocation. Cancer 2008;113(8 Suppl):2244-56.

[9] Odusanya 00, Tayo 00. Breast cancer knowledge, attitudes and practice among nurses in Lagos, Nigeria. Acta Oncol 2001;40(7):844-8.

[10] Fotedar V, Seam RK, Gupta MK, et al. Knowledge of risk factors \& early detection methods and practices towards breast cancer among nurses in Indira Gandhi medical college, Shimla, Himachal Pradesh, India. Asian Pac J Cancer Prev 2013;14(1):117-20.

[11] Akhigbe AO, Omuemu VO. Knowledge, attitudes and practice of breast cancer screening among female health workers in a Nigerian urban city. BMC Cancer 2009;9:203.

[12] Rao RS, Suma N, Nair NS, et al. Acceptability and effectiveness of a breast health awareness programme for rural women in India. Indian J Med Sci 2005; 59(9):398-402.

[13] Okobia MN, Bunker CH, Okonofua FE, et al. Knowledge attitude and practice of Nigerian women towards breast cancer: a cross sectional study. World J Surg Oncol 2006;4:11.

[14] World Health Organization. Cancer control: knowledge into action: WHO guide for effective programmes; module 3. Geneva. WHO; 2007.

[15] Vidyarthi A, Soumya A, Choudhary S, et al. Barriers to breast cancer screening in young Indian women: a tale of two cities. Asian J Exp Sci 2013;27:29-35. 